\title{
The Maternal Deaths at the Obstetrics and Gynaecology Department of the Ignace Deen National Hospital, University Teaching Hospital (CHU) Conakry, Guinea
}

\author{
Boubacar Siddi Diallo1* ${ }^{*}$ Mamadou Hady Diallo', Ousmane Balde1, Ibrahima Sylla², \\ Ibrahima Conte ${ }^{2}$, Abdourahmane Diallo², Oumou Hawa Bah1, Saran Camara1, \\ Ibrahima Sory Balde ${ }^{2}$, Telly Sy², Yolande Hyjazi' ${ }^{1}$, Namory Keita ${ }^{1}$ \\ ${ }^{1}$ University Department of Gynecology-Obstetrics, Donka National Hospital, Conakry, Guinea \\ ${ }^{2}$ University Department of Gynecology-Obstetrics, Ignace Deen National Hospital, Conakry, Guinea \\ Email: *tounty1@yahoo.fr, hadydiallo@yahoo.fr, baldeousmane04@gmail.com,dribra62@yahoo.fr, conteib1976@gmail.com, \\ adiallo69gn@yahoo.fr, camarahawa2002@gmail.com, sarancamara88@yahoo.fr, baldeisory@yahoo.fr, sytelly@yahoo.fr, \\ namoryk2010@yahoo.fr
}

How to cite this paper: Diallo, B.S., Diallo, M.H., Balde, O., Sylla, I., Conte, I., Diallo, A., Bah, O.H., Camara, S., Balde, I.S., Sy, T., Hyjazi, Y. and Keita, N. (2019) The Maternal Deaths at the Obstetrics and Gynaecology Department of the Ignace Deen $\mathrm{Na}-$ tional Hospital, University Teaching Hospital (CHU) Conakry, Guinea. Open Journal of Obstetrics and Gynecology, 9, 597-603. https://doi.org/10.4236/ojog.2019.95058

Received: March 21, 2019

Accepted: May 10, 2019

Published: May 13, 2019

\section{Copyright $\odot 2019$ by author(s) and} Scientific Research Publishing Inc. This work is licensed under the Creative Commons Attribution International License (CC BY 4.0).

http://creativecommons.org/licenses/by/4.0/

(c) (i) Open Access

\begin{abstract}
Objectives: 1) To calculate the ratio of maternal mortality. 2) To describe the socio-demographic characteristics of deceased patients. 3) To identify the main causes of maternal deaths. Methodology: This was a retrospective study of the 12-month period from January $1^{\text {st }}$ to December $31^{\text {st }}, 2015$ performed at the Gynaecology Obstetrics Department of the Ignace Deen National Hospital, Conakry, Guinea. The study included women who died during pregnancy, childbirth, and in its peripheries according to WHO's maternal death report. Results: We collected 38 cases of maternal deaths out of 4404 live births, accounting a ratio of 863 per 100,000 live births. The socio-demographic characteristics of these 38 patients were: 20 - 24 years of age (26\%), married (78\%), housewives (37\%), students (44\%), and nulliparous (29\%), no prenatal follow-up (47\%), and home-birth $(49 \%)$. The $1^{\text {st }}$ and $3^{\text {rd }}$ type of delay amounted for $40 \%$ and $53 \%$, respectively. Patients consulted after 12 hours after symptom-onsets accounted 47\%, whereas those before 6 hours accounted for $19 \%$, suggesting the delay of first medication. The final diagnosis and diagnosis at admission coincided in $69 \%$ of cases. The emergency kit was available for all. The opinion of a specialist was available in 16 patients. Blood was available in $40 \%$ of the patients who required it. Death caused by conditions directly related to pregnancy/delivery accounted for $71 \%$. Haemorrhage was the most frequent cause of death. Death occurred within the first 24 hours of admission in $73 \%$ of cases. Conclusion: We here shed light on the
\end{abstract}


maternal death in this area. Although we did not demonstrate the method/procedure to reduce this high rate of maternal mortality, the present study may provide a fundamental data to reduce maternal death in this area.

\section{Keywords}

Review, Maternal Deaths

\section{Introduction}

According to the world health organization, the maternal mortality is the death of woman during the pregnancy or within the 42 days after the termination whatever the duration and the place for any particular cause of aggravated pregnancy by the care that it motivated, but neither accidental nor fortuitous [1]. The death of a woman in the gravid-puerperal period is still experienced as a tragedy [2]. Nearly 600,000 maternal deaths occur worldwide every year. $99 \%$ of these cases occur in developing countries [3]. About 30\% of maternal deaths occur in South Asia and 60\% in sub-Saharan Africa [4]. In Egypt, the maternal mortality rate was around 33 per 100,000 live births (N.V) in 2015 [3]; in Tunisia, 62 per 100,000 NV in 2015 [5]; in Gabon, 291 per 100,000 NV in 2015 [6]; in Côte d'Ivoire (Ivory Coast), 645 per 100,000 NV in 2015 [7]; in Guinea, according to the 2015 EDS, 679 maternal deaths per 100,000 NV [8] against 724 per 100,000 $\mathrm{NV}$ in 2012 [9]. This case is generally related to the shortcomings in the supply of services at various levels, leading to one of the three delays: the first, ignorance of the signs of danger and traditional treatment; the second, lack of means of transportation and communication; and the third, lack of competent staff, delay in the care, total and/or partial unavailability of blood products and consumables. At the Yopougon Hospital [7], the first delay was 72\% in 2008.

The objectives of this work were to:

- calculate the ratio of intra-hospital maternal mortality;

- describe the socio-demographic characteristics of the deceased patients;

- identify the main causes of maternal deaths;

$\circ$ identify the three delays leading to maternal death.

\section{Methodology}

This was a retrospective study of the 12-month descriptive type, from January 1st to December 31, 2015, performed at the Obstetrics and Gynaecology Department of the Ignace Deen National Hospital, CHU of Conakry. The study included women who died during pregnancy, childbirth, and in the peripheries according to the WHO's definition of maternal death. It consisted in examining the hospitalization records for each case by a review committee made up of obstetrician gynaecologists, midwives and paediatricians. Variables were epidemiological (age, occupation, educational level, marital status, parity, source, prena- 
tal follow-up, and death period), clinical (reasons for consultation, evolution, concordance between discharge and admission diagnoses, availability of kits, solicitation of other specialties, treatment received, type of surgery, respectability of requests for blood, delays and avoidability) and etiological.

\section{Results}

\subsection{Epidemiology}

- Ratio: We collected 38 cases of maternal death for 4404 Births, a ratio of 863 per 100,000 NV.

- Age: Patients in the age group of 20 - 24 were the most affected $(26.33 \%)$ with an average of 26.26 years and extremes of 15 and 42 years.

- Profession: Housewives were the most concerned with $37 \%$.

- Level of education: The largest number of women who died was did not go to school, $44 \%$.

- Marital status: Married women (78\%) were the most concerned.

- Parity: The nullipares were the most represented, i.e. $28.92 \%$.

- Pregnancy follow-up: Eighteen patients (47\%) who had died had no prenatal consultation.

\subsection{Clinical}

1) Reasons for consultation: $37 \%$ of the deceased patients were admitted for haemorrhage followed by hypertension and its complications (eclampsia) (26\%).

2) Evolution: $47 \%$ of the patients were consulted only after the $12^{\text {th }}$ hour against $19 \%$ before the $6^{\text {th }}$ hour.

3) Concordance between diagnosis of evacuation and admission: In $69 \%$ of the cases the diagnoses corresponded.

4) Availability of emergency kits: It was available for all deceased patients.

5) Solicitation of other specialties: In our study $42 \%$ of deceased patients had benefited from the demand for other specialties and $43.5 \%$ had a favorable response.

6) Honorability of the blood demand: the blood requests of $40 \%$ of the deceased patients were honored.

7) Delays: The 1st and 3rd delays were the most incriminated with respectively: $39.47 \%$ and $52.63 \%$.

8) Causes of death: Deaths were due to direct causes in $71 \%$ of cases against $29 \%$ for indirect ones.

9) Preventable or not: In $68 \%$ of the cases the deaths were avoidable compared to $32 \%$.

\section{Discussion}

\subsection{Epidemiology}

Ratio: We collected 38 maternal deaths for 4404 Live Births, a ratio of 863 per $100,000 \mathrm{NV}$. This result is close to the 724 deaths per $100,000 \mathrm{NV}$ of the EDS4 
Guinea 2012 [8], well below the 1060 per 100,000 NV found by BALDE IS in 2012 in Donka (Guinea) [10] and the triple of 288 for 100,000 NVs found by Gandzien [4] in Congo Brazzaville in 2005.

This ratio would be related to the last-resort level of service in the country's health pyramid with limited resources, receiving serious emergencies including “desperate ones".

1) Age: Patients in the age group of 20 - 24 were the most affected (26.33\%) with an average of 26.26 years and extremes of 15 and 42 years. This average corresponds to that recorded in 2004 in the Ivoirian series [7] and lower than that found by BALDE IS in 2012 in Donka (Guinea) [10].

2) Profession: Housewives were the most concerned with $37 \%$. The finding is similar to that found by BALDE IS in 2012 in Donka (Guinea) [10] and those in the sub-region $(7,8,9)$. This high proportion is linked to the low income in this group and the influence of the family in decision-making to consult in a health facility.

3) Level of education: The largest number of women who died was out of school, i.e. $44 \%$. This rate of out-of-school women is in line with that of the general population in Guinea, where $74 \%$ of illiterates are women, $85.3 \%$ of whom are female, according to the Guinean EDS4 [8].

4) Marital Status: Married women (78\%) were the most concerned. This result is close to the one found by BALDE IS in 2012 in Donka (Guinea) [10] or $87.50 \%$. This would be linked on the one hand to polygamy and on the other hand to the fact that in our regions, the marriage is the only legal way to give birth. The statement is similar to those of others [1] [2] [6] [12].

5) Parity: nullipares were the most represented or $28.92 \%$. For N'guessan et al. [13] maternal death increases with parity. These nulliparas are most often teenagers, who are not in school, therefore little aware of the need to watch over their state of health.

6) Prenatal follow-up: the absence of prenatal follow-up would be a predisposing factor to death during the gravid-puerperal period with $47 \%$ of our study population. This result is close to the one found by Balde IS in 2012 in Donka (Guinea) [10] or $57.90 \%$ and superimposed on those of some authors in the sub region [7] [12] [14] but triple that reported by Horo [13] in 2008 in Ivory Coast. WHO has recommended since 1998 a minimum of 4 ANC during pregnancy. However, it should be noted that the number of antenatal care does not protect the pregnant from death but rather the quality of it and especially the period in which they are performed. This high frequency could be explained by the fact that these patients are unaware of the benefits of antenatal care.

\subsection{Clinical}

1) Reasons for consultation: The occurrence of the maternal death would be related to the reason for consultation of the victim. In our series, 37\% of the deceased patients were admitted for haemorrhage. The finding was similar in Gabon [6] and Algeria [11] in 2011 with $40 \%$ and 50\% respectively. This high fre- 
quency could be explained by the place of haemorrhage in the causes of death.

2) Evolution: The delay between the onset of symptoms and consultation predisposes to maternal death. In our study, $47 \%$ of the deceased had consulted a health facility only after the 12th hour of the appearance of the first symptom. This result corresponds to that found by BALDE IS in 2012 in Donka (Guinea) [10] or $47.50 \%$. This is also the observation in the Ivorian series [7] in 2008 with $78.69 \%$. In our regions, women, even salaried workers, do not enjoy autonomy in decision-making.

3) Concordance between evacuation diagnoses and admission: The two diagnoses were consistent in $69 \%$ of cases in our study is similar to that found by BALDE IS in 2012 in Donka (Guinea) [10] or 67.9\%. The finding is similar in several series [3] [10] [15]. This high proportion would be due to the multiple training courses in basic obstetric and neonatal care and the complete ones organized for the staff of peripheral maternity hospitals.

4) Availability of emergency kits: The availability of emergency products would improve the management of patients. In our study, it was available to all deceased patients. This is to the credit of the rulers who have decreed free obstetric and neonatal care.

5) Solicitation of other specialties: In our study $42 \%$ of deceased patients had benefited from the demand for other specialties and $43.5 \%$ had a favorable response. In his series BALDE IS in 2012 in Donka (Guinea) [10] found 27.5\% of demand and $45.5 \%$ of favourable response. This result is linked, on the one hand, to the reduced number of staff in the guards and on the other to the lack of promptness of the staff in the inter-disciplinary exchanges.

6) Blood products: $40 \%$ of the deceased patients had obtained blood. This result is super imposable to that found by BALDE IS in 2012 in Donka (Guinea) [10] or $42.9 \%$. This situation would be due to repeated stock outs of blood products, the inability of families most often to find 2 donors for a blood bag, provisions in force at the national centre of blood transfusion.

7) Delays: The 1st and 3rd delays were the most incriminated with respectively: 39.47\% and 52.63\%, even observed by BALDE IS in 2012 in Donka (Guinea) [10] or $87.5 \%$ for each of the delays (1st and 3rd delays). For Gunawan et al. [16]. In 2002, in Indonesia, 76.70\% of deaths were related to the first delay. This first delay could be explained by the inadequacies in the supply of refocused CPNs during which the signs of seriousness are explained to the pregnant and/or influential member of her family or to a poor application of these of their family share.

8) Cause of death: Deaths were due to direct causes in $71 \%$ of cases against $29 \%$ for indirect ones. This result is similar to that found by BALDE IS in 2012 in Donka (Guinea) [10] or 65\% of cases and in the WHO literature [16]. Haemorrhage ranks first in our series or $37 \%$. It is similar in the studies of Dellagi RT [5] in Tunisia and Horo [7] in Cote d'Ivoire with lower proportions. However, for Benmouhoud [11] in Algeria in 2011, haemorrhages ranked 2nd with 
$16.60 \%$.

9) Preventable or not: Deaths are generally preventable but at various proportions: $68 \%$ in our study, 87.50\% in the BALDE IS series in 2012 in Donka (Guinea) [10], 49\% and 100\% respectively for Horo et al. [7] and Bouvier Colle et al. [7] in 2008.

\section{Conclusion}

The reduction of this ratio would be through the provision of refocused prenatal consultation, comprehensive emergency obstetric and neonatal care, the refreshing of providers of basic facilities, and the speed with which care is taken immediately upon admission of emergencies and the availability of blood products.

\section{Conflicts of Interest}

The authors declare no conflicts of interest regarding the publication of this paper.

\section{References}

[1] WHO (2000) WHO/UNFPA/World Bank Joint Statement. Reducing Maternal Mortality, Geneva, 6186622.

[2] Bouvier Colle, M.H., Deneux, T.C., Couet, C. and Michel, E. (2004) Estimation of Maternal Mortality in France: A New Method. Journal de Gynécologie Obstétrique et Biologie de la Reproduction, 33, 421-429. https://doi.org/10.1016/S0368-2315(04)96550-7

[3] Ben Salem, J., Jmal, A. and Aifum, C. (2006) Epidemiology of Maternal Mortality at the Monastir CHU. Maghrebian Journal of Anaesthesia-Rehabilitation and Emergency Medicine, 13, 8-10.

[4] Gandzien, P.C. (2005) Maternal Mortality in Hospital of Brazzaville Talangai. Médecine d Afrique Noire, 52, 657-660.

[5] Dellagi, R.T., Belgacem, M., Hamrouni, M. and Zouari, B. (2008) Assessment of Maternal Death Tracking System in Public Structures in Tunis (1999-2004). Eastern Mediterranean Health Journal, 14, 1380-1390.

[6] Mayi-Tsonga, S., Okasana, L., Diallo, T., Methogo, M., Ndombi, I., Mendome, G., et al. (2010) Study on Maternal Deaths at the Hospital Center of Libreville. Médecine d Afrique Noire, 57, 8-9.

[7] Horo, A.G., Toure-Ecra, F., Mohamed, F., Adjoussou, S. and Koné, M. (2008) Malfunctioning and Maternal Mortality: Analysis of 35 Cases at the Maternity Hospital of Yopougon University Hospital (Abidjan, Ivory Coast). Médecine dAfrique Noire, 55, 449-453.

[8] National Directorate of Statistics (Guinea) (2013) Demographic and Health Survey and Multiple Indicators (EDS-MICS, 2015). National Statistical Institute, Conakry, MEASURE, DHS, International ICF, Calverton, 243-247.

[9] National Directorate of Statistics (Guinea) (2012) Demographic and Health Survey III (EDS-MICS, 2012). National Statistical Institute MEASURE, DHS, International ICF, Calverton, 1-13.

[10] Balde, I.S., Balde, O., Camara, M.K., Diallo, A., Diallo, M.H. and Diallo, B.S. (2016) 
Maternal Death Review at the Gynecology and Obstetrics Department of Donka National Hospital, Conakry Teaching Hospital (Guinea). RISM, 18.2, 99-103.9.

[11] Benmouhoud, N. (2010) Maternal Mortality in Algeria. Maghreb Journal of Anesthesia Punishment and Emergency Medicine, 17, 225-227.

[12] Bah, A.O., Diallo, M.H. and Conde, A.M. (2001) Arterial Hypertension and Pregnancy: Maternal and Prenatal Mortality. Médecine d Afrique Noire, 48, 461-464.

[13] N'guessan, E., Bouhoussou, P.E. and Toure, B. (2010) Risk Factors of Maternal Mortality among Teenagers: About 60 Cases Collected. Medicine of Black Africa, 57, 521-526.

[14] Lankoande, J., Ouedraogo, C., Toure, B., Ouedraogo, A., Dao, B. and Kone, B. (1998) Mortal Mortality at the Maternity Hospital of the National Hospital of Ouagadougou (Burkina Faso): About 123 Cases Collected 1995. Médecine d Afrique Noire, 3, 187-190.

[15] Ouedraogo, C., Ouedraogo, A., Ouattara, T., Ako, T., Nga, M., Thieba, B., et al. (2001) Maternal Mortality in Burkina Faso: Evolution and National Struggle Strategy. Médecine d' Afrique Noire, 48, 36-39.

[16] Gunawan, S., Meg, E.W. and Endang, A.A. (2002) District Based on Kalimantan, Indonesia. Bulletin of the World Health Organization, 80, 142-145. 